\title{
ADHD Assessment and Diagnosis in Canada: An Inconsistent but Fixable Process
}

\author{
Alan Edmunds \& Shelley Martsch-Litt \\ University of Western Ontario
}

\begin{abstract}
Canadian teachers in inclusive classrooms are encountering more students with ADHD-like behaviours and making more referrals for formal diagnosis of the condition. Previous research suggests that ADHD diagnoses are susceptible to highly inconsistent and arbitrary assessment processes/criteria (Sanford \& Ridley, 1995), thus probably contributing to teachers' lack of effective interventions. This study sought to establish whether Canadian ADHD diagnosticians were specifically identified, whether common diagnostic criteria/guidelines were used, and whether diagnostic processes were empirically grounded. One-hundred and seventy-six official documents from the prominent Canadian organizations vested in ADHD diagnosis were examined. The results revealed that various professionals provide ADHD diagnoses, that few organizations had clear diagnostic guidelines, and that few organizations outlined theoretical foundations for ADHD aside from references to DSM-IV-TR criteria. This evidence suggests a three-fold potential for compounding inconsistencies in ADHD diagnoses. Recommendations for standardized criteria and processes to remediate these pervasive inconsistencies are provided.
\end{abstract}

A review of the current literature on inclusion reveals that the vast majority of teachers are trying to cope with escalating numbers of students who have a variety of exceptional learning and behavioural needs. In particular, students with Attention Deficit Hyperactivity Disorder (ADHD) are increasingly referred for formal assessments because teachers find it especially difficult to deal with their persistent attentional and behavioural deficits, which require enormous amounts of educator monitoring and intervention (Baum \& Olenchak, 2002). ADHD is a disorder wherein individuals consistently demonstrate a specific set of clinically observable behaviours as identified by the Diagnostic and Statistical Manual of Mental Disorders-IV (DSM-IV-TR; American Psychiatric Association, 2000). Behaviourally, the diagnosis encompasses symptoms of inattention, impulsiveness, and hyperactivity that significantly interfere with 
an individual's relationships and educational and occupational functioning. The criterion behaviours of the DSM-IV-TR are behaviours that everyone engages in from time-to-time- the distinguishing difference being that individuals with ADHD exhibit these behaviours more frequently, often under inappropriate circumstances, and these behaviours are usually accompanied by higher-than-would-be-expected emotional intensity that persists long after the incident has passed. Thus, ADHD is categorized by a clinical set of behaviours according to frequency, intensity, duration, and appropriateness. For the most part, individuals with ADHD do not have regulatory systems that can control these behaviours caused by a deficiency, imbalance, or inefficiency in brain chemicals that affect certain brain regions (Rief, 2005). In addition to behavioural indicators, there is mounting evidence that individuals with ADHD also have common cognitive deficits that negatively impact their performance in school. ADHD is associated with functional differences in the psychological processes of executive functioning, working memory, learning efficiency, and information processing (Castellanos \& Tannock, 2002; Martinussen, Hayden, Hogg-Johnson, Tannock, 2005; McInnes, Humphries, Hogg-Johnson, Tannock, 2003; Seidman, 2006; Willcutt, Pennington, Olson, Chhabildas, \& Hulslander, 2005).

According to Goldstein (1995), teachers spend significant amounts of time attending to disruptive behaviour; there are more negative teacher-child interactions involving other students in classrooms containing children with ADHD, and children with ADHD are exposed to higher occurrences of negative interactions compared with other students. Also, children with ADHD are often more interested in tasks other than those provided by teachers, which contributes to significantly less productive time on academic tasks. Further, DuPaul, Eckert, and McGoey (1997) reported that students with ADHD displayed higher than average rates of calling out, interrupting activities, getting out of assigned seats, and not completing assigned tasks. Children with ADHD also demonstrate such unpredictable patterns of behaviour that teachers erroneously conclude that these students are noncompliant rather than incompetent, despite the well documented fact that the absence of good behaviour is a skill performance problem - not a skill deficit problem (Gresham, 2002; Lane, Falk, \& Wehby, 2006; Maag, 2004). An increasing percentage of students diagnosed with ADHD experience reduced academic achievement, negative teacher and peer interactions, and low self-esteem; at the same time, overextended and frustrated teachers are regularly dealing with disruptive children (Baum \& Olenchak, 2002). A recent World Federation for Mental Health (2004) study highlighted the experiences of individuals and families affected by ADHD in nine different countries, including Canada. The results revealed that from the time of their first contact with a professional due to ADHD symptoms, Canadian children waited an average of 1.59 years to be officially diagnosed: $56 \%$ waited less than 12 months while $30 \%$ waited more than two years. The results also indicated that $69 \%$ of Canadian parents were stressed or worried about their child's ADHD.

Researchers have noted the rising prevalence of ADHD (Zentall \& Stormont-Spurgin, 1995) wherein $9.2 \%$ of males and $2.9 \%$ of females exhibited ADHD behaviours (American Academy of Pediatrics, 2002). Prevalence statistics for Canadian children with ADHD, or with other exceptionalities, are difficult to determine because, according to Edmunds and Edmunds (2008),

Canada does not have a process that parallels the federal function of the United States Department of Education which, in its annual report to the US Congress, tracks the number of students with disabilities who receive special education funding and services (p. 20). 
Nonetheless, the Centre for ADHD/ADD Advocacy Canada (CADDAC, 2007) reported that studies throughout the world have reported that the occurrence of ADHD is between 5\% and 12\%; two Canadian studies reported similar prevalence rates of $8.9 \%$ (Breton et al., 1999) and 5.8\% (Szatmari, Offord, \& Boyle, 1989). Finally, a recent investigation of the worldwide prevalence of ADHD found that there was no convincing difference between the prevalence of ADHD in the United States and most other countries (Faraone, Sergeant, Gillberg, \& Biederman, 2003).

In a comprehensive review of assessment and intervention procedures, Lane et al. (2006) reported that functional assessment-based interventions were increasingly found to be effective for students with ADHD. The primary focus of a functional behavioural assessment is to identify the causal or functional relationship that potentially exists between the observed problem behaviours and the child's immediate environment. This approach also considers the child's repertoire of skills (or lack thereof) and the views and feelings of the child in rendering a diagnosis.

The formal assessment of ADHD is necessary if appropriate interventions are to be properly designed and implemented. However, it is difficult to have confidence in the process or its resultant interventions when diagnoses and interventions appear to depend on the arbitrary selection of behavioural symptoms and criteria (Sanford \& Ridley, 1995). The possibility of a nonstandardized approach occurs because professionals involved in diagnosing ADHD are allowed wide-ranging interpretations of ADHD diagnostic criteria due to long standing disagreements about its neurological, biological, and/or environmental etiology. As a result, the ADHD definition and diagnostic criteria have changed frequently, resulting in multiple views leading to inconsistencies in diagnoses and interventions, and probably contributes to the prevalence discrepancies often reported across studies (Sanford \& Ridley, 1995). Moreover, the most recurring theme in current ADHD research is increased discussion about its diagnosis processes, tools, and criteria, and in the United States, ADHD is both the most extensively studied and most controversial mental disorder. Wolraich (2002) encapsulated the discussion:

...with services for children with ADHD spanning the general medical, mental health and educational sectors of a community and including constitutional and environmental issues, it is not surprising that there are differences of opinion about the condition and its diagnosis and treatment (p. 469).

Physicians play a predominant role in the diagnosis and treatment of ADHD, but often do not employ the best available diagnostic practices because they are alone in their attempts to make sense of the myriad of information to arrive at an accurate diagnosis (Wolraich, 2002). The problems associated with a non-standardized diagnostic process for ADHD were so significant that the American Academy of Pediatrics developed diagnostic guidelines and offered specific ADHD training for all physicians in 2002.

While the United States appears to be attempting to clarify the diagnostic structures of $\mathrm{ADHD}$, the literature regarding Canadian practices suggests much work is needed. Other than policies and guidelines found in medical association documents, there is little empirical evidence about ADHD diagnostic structures in Canada. Anecdotally, Canadian educators have lamented about wide variations in how students present with ADHD and the many inconsistencies in its assessment and diagnosis, that nearly all diagnosticians are external to education, and that the diagnosis is separated from all other educational procedures-especially academic instruction. As a result, Canadian educators struggle with the effects of inconsistently prescribed interventions and little collaboration with diagnosing professionals. The only research on ADHD 
assessment and diagnosis in Canada that we were able to find was the 1998 study completed by Cohen and colleagues (reported in Cohen, 2006). In that research, the process of assessing and diagnosing ADHD was part of several factors systematically examined to explore how and why there was a preponderance of medication-only interventions for children who presented ADHD symptoms. Cohen's data revealed that the professionals involved in the diagnosis (including physicians) bemoaned the absence of a consistent assessment approach, criticized the shortcomings of popular ADHD rating scales, unanimously described the diagnosis as ambiguous and complicated, and described the overall process as unfit to respond adequately to the needs of referred children. In addition to an absence of delineated functions for the assessment instruments used by diagnosticians, Cohen reported that teachers viewed their participation in the process as limited and inadequate and that all teachers emphasized the irrelevance of assessment results because the results simply repeated what teachers already knew/told the diagnosticians. While parents specifically indicated that assessment results were uninformative relative to their child's overall needs, all affected groups in the study expressed considerable dissatisfaction with the assessment process. One of the proposed solutions by primary-care physicians was the improvement of their evaluations of the disorder via better tests to increase the validity of their diagnoses, and they joined with all other participant groups in a call for increased solidarity to improve the assessment process.

Given that there are various possible approaches and outcomes, we wondered whether Canadian professionals had access to clear implementation guidelines for assessing and diagnosing ADHD. If they did, we wondered how purposefully Canadian professionals utilized these guidelines in their diagnostic process. Therefore, the primary objective of this research was to examine the diagnostic criteria and theoretical foundations clinicians are provided regarding ADHD. A unified understanding would enable professionals to improve the overall process, result in more effective interventions, and enable educators to provide students with more appropriate learning environments.

\section{The ADHD Definition}

A brief history of the definition is provided to illustrate why ADHD is a construct that elicits misinterpretations and is susceptible to interpretation. Throughout the last 100 years, ADHD was called by many names, its definition changed several times, and its diagnostic criteria were revised five times. In the early 1900 s, researchers observed that a variety of conditions that affected the brain (tumors and infections) led to abnormalities in behaviour, such as hyperactivity and inattention, and these problems became more evident when affected children began school (Mercugliano, Power, \& Blum, 1999). During the 1917-18 encephalitis outbreak, clinicians saw numerous children who survived this brain infection, but were left with impairments in attention and the regulation of activity and impulse control-behaviours still incorporated in the current definition (Barkley, 1990). The disorder was called Post-encephalitic Behavior Disorder and was thought to be the result of central nervous system damage. In the 1940s, scientists hypothesized that individuals with these behaviours had incurred brain damage; therefore, the term Minimum Brain Damage (MBD) was used. In the 1960s, MBD changed to Minimum Brain Dysfunction because some individuals with identical symptoms had no brain injuries (Mercugliano et al., 1999) and researchers seriously questioned the notion of inferred brain damage where no history of damage existed (Barkley, 1990). As a result, Minimum Brain Dysfunction was defined 
as a heterogeneous disorder that included children with learning difficulties as well as those with short attention spans, hyperactivity, and impulsivity. Ongoing attempts to divide MBD into homogeneous subgroups played an important role in distinguishing between learning disabilities and inattention, hyperactivity, and impulsivity (Mercugliano et al., 1999).

\section{$A D H D$ Criteria in the DSM I, II, III, III-R, IV, \& IV-TR}

The Diagnostic and Statistical Manual of Mental Disorders (DSM-I; American Psychiatric Association, 1952) was created by the American Psychiatric Association to establish a uniform system for classifying all mental disorders and to guide clinicians through respective diagnostic processes (Anastopoulos \& Shelton, 2001). The DSM-I and DSM-II were influenced by the psychodynamic approach which did not distinguish between normal and abnormal behaviour, wherein all disorders were considered an individual's reaction to his/her environment. There were no guidelines for diagnosing children or adolescents because psychiatrists of the time believed children did not have the psychological capacity to experience mental problems. However, two events in the 1960s situated ADHD in the DSM: child and adolescent mental problems were acknowledged, and North America and Great Britain rejected the International Classification of Diseases standards of the World Health Organization and began exclusively using DSM criteria for assessing and diagnosing ADHD (Barkley, 1990).

As a result, the DSM-II (American Psychiatric Association, 1968) was the first official document to provide guidelines for ADHD diagnosis and all but one of its subsequent editions revised the ADHD criteria. In the DSM-II era, a hyperactive child was defined as one who carries out activities at a higher than normal rate of speed than the average child, or who is constantly in motion, or both, resulting in the label Hyperkinetic Reaction of Childhood. However, the DSM-II only briefly described activity levels without providing specific details for a reliable diagnosis; therefore, diagnosis was largely based on a clinician's judgment as to whether the child matched the criteria. This variability opened the door to unacceptably low diagnosis reliability due to clinicians' conceptions of ADHD and inaccurate diagnoses readily occurred (McBurnett, Lahey, \& Pfiffner, 1993). Despite its ambiguities, the DSM-II was historically significant because (a) the diagnostic criteria were based on behavioural characteristics, (b) the defined behaviours separated hyperactivity from brain damage syndrome, and (c) the criteria provided a more objective measure of ADHD than previous iterations. Unfortunately, this was also the time when experts started believing that symptoms were either outgrown by puberty or that impulsivity and inattention persisted into adolescence/adulthood (Anastopoulos \& Shelton, 2001). Some researchers believe this issue is not resolved today.

In the 1970s, many researchers challenged the disorder's conceptual basis arguing that its symptoms were poorly defined, did not inter-correlate significantly, had no specified etiology, and that the disorder displayed no common course or outcome. As a result, the DSM-III (American Psychiatric Association, 1980) broadened the guidelines into a multi-axial system and outlined specific criteria to diagnose two subtypes of Attention Deficit Disorder: ADD with, or without, hyperactivity. Fourteen identifying behaviours were separated into three categories: (a) five symptoms of inattention, (b) five symptoms of impulsivity, and (c) four symptoms of hyperactivity. This increased the number of diagnostic decisions from 1 (Is the syndrome present?) to 14 (Is each individual symptom present?) and increased diagnostic reliability. These guidelines 
also specified age of onset (before 7 years of age), the duration of symptoms (at least 6 months), and the exclusion of other psychiatric conditions as diagnostic criteria (McBurnett et al., 1993).

In 1987, the researchers responsible for the DSM-III-R (American Psychiatric Association, 1987) felt there was insufficient evidence for subtyping ADD and determined that any eight symptoms were sufficient to meet the criterion for Attention Deficit Hyperactivity Disorder (ADHD). They classified ADHD with Oppositional Defiant Disorder and Conduct Disorder under Disruptive Behavior Disorders because of considerably overlapping characteristics in referred children (Barkley, 1990). The DSM-III authors felt the ADD definition excluded too many children with attention problems who were not hyperactive and ADD without hyperactivity was reclassified as Undifferentiated ADD (Roberts, Humphries, \& Andras, 1989). However, Undifferentiated ADD proved too difficult to diagnose because no list of identifying symptoms was presented (Shea \& Baren, 1996) and clinicians were forming impressions of children based on a haphazard collection of data (Roberts et al., 1989).

Today's 18 behavioural criteria of ADHD were established in 1994 in the DSM-IV (American Psychiatric Association, 1994) and presented ADHD as a disorder with three subtypes: inattention (nine symptoms) and hyperactivity/impulsivity (nine symptoms). Inattention, according to Silver (1999), refers to individuals who have short attention spans and difficulty staying on task; the most frequent problem being an inability to block out unimportant stimuli and being distracted. Hyperactivity refers to individuals who are fidgety, restless, exhibit squirmy behaviours, and who appear to be in constant motion, whereas impulsivity refers to individuals who talk or act before reflecting on the consequences of their actions such as calling out and/or interrupting others (Silver, 1999).

In 2000, the DSM-IV-TR (American Psychiatric Association, 2000) was a text-only revision and the 18 behavioural criteria for ADHD went unchanged. In Mather and Goldstein's (2001) critique of the topic, they felt it was unfortunate that the criteria continued to focus on inattention because this limited the discipline's focus on the considerable negative impact of impulsive behaviours. Instead, they suggested that ADHD-Predominantly Inattentive Type was a distinct disorder that reflected difficulty with organization and attention to repetitive, effortful tasks, and that inattentiveness was more the result of faulty skills than improper skill use.

In summary, it is evident that the current ADHD diagnostic criteria resulted from major conceptual shifts and an increased emphasis on subtyping. Anastopoulos and Shelton (2001) strongly stated that it was the practitioner's responsibility to adhere closely to these guidelines to reduce variability in implementation. The DSM-IV-TR does not, however, specify a preferred procedure by which the criteria are used; therefore, implementation and diagnoses are subject to interpretation.

\section{Current ADHD Diagnosis Criteria}

To diagnose ADHD, six of nine criterion in A or B must be present for at least 6 months and cause significant impairment in at least two settings (school, home, work, leisure; American Psychiatric Association, 2000). The diagnosis can result in three different subtypes: (a) ADHD, Predominantly Inattentive Type; (b) ADHD, Predominantly Hyperactive-Impulsive Type; and (c) ADHD, Combined Type. 


\section{DSM-IV-TR Criteria for Diagnosing ADHD}

Either $\mathrm{A}$ or $\mathrm{B}$ :

A. Six or more of the following symptoms of inattention have been present for at least 6 months to a point that is disruptive and inappropriate for developmental level:

Inattention

1. Often does not give close attention to details or makes careless mistakes in schoolwork, work, or other acti vities.

2. Often has trouble keeping attention on tasks or play activities.

3. Often does not seem to listen when spoken to directly.

4. Often does not follow instructions and fails to finish schoolwork, chores, or duties in the workplace (not due to oppositional behavior or failure to understand instructions).

5. Often has trouble organizing activities.

6. Often avoids, dislikes, or does not want to do things that take a lot of mental effort for a long period of time (such as schoolwork or homework).

7. Often loses things needed for tasks and activities (e.g. toys, school assignments, pencils, books, or tools).

8. Is often easily distracted.

9. Is often forgetful in daily activities.

B. Six or more of the following symptoms of hyperactivity-impulsivity have been present for at least 6 months to an extent that is disruptive and inappropriate for developmental level:

Hyperactivity

1. Often fidgets with hands or feet or squirms in seat.

2. Often gets up from seat when remaining in seat is expected.

3. Often runs about or climbs when and where it is not appropriate (adolescents or adults may feel very restless).

4. Often has trouble playing or enjoying leisure activities quietly.

5 . Is often "on the go" or often acts as if "driven by a motor".

6. Often talks excessively.

Impulsivity

7. Often blurts out answers before questions have been finished.

8. Often has trouble waiting one's turn.

9. Often interrupts or intrudes on others (e.g., butts into conversations or games).

Additional Considerations

1. Some symptoms present before age 7 .

2. Symptoms do not occur as part of Pervasive Developmental Disorder, Schizophrenia, or other Psychotic Disorder and/or are not better explained by other mental disorder (e.g. Mood Disorder, Anxiety Disorder, Dissociative Disorder, or Personality Disorder).

3. Adolescents with symptoms under control can be designated "in partial remission"

4. Children with few but especially prominent symptoms can be designated ADHD not otherwise specified.

Given that numerous researchers in the discipline have called for closer adherence to ADHD criteria to reduce diagnostic variability, research into the ADHD diagnostic process in Canada was warranted. Therefore, based on all the research outlined in the preceding sections, the purpose of this study was to determine who in Canada was responsible for diagnosing ADHD, what criteria were used in the diagnosis, whether the criteria were underpinned by established theoretical foundations, and whether the evidence about the above revealed a consistent approach to assessing and diagnosing ADHD. 


\section{Method}

To determine the criteria, guidelines, and processes used to diagnose ADHD in Canada, we examined primary and secondary source documents containing behavioural criteria, guidelines, or policies influencing the ADHD diagnostic process. The documents were categorized according to the five principal groups that have direct interest in, and/or direct influence upon, the assessment and diagnosis of ADHD. Group One consisted of 30 government agencies: 15 federal, provincial, territorial ministries of health; and 15 federal, provincial, territorial ministries of education. Group Two consisted of 30 medical associations: Canadian Paediatric Society, Canadian Psychiatric Association, provincial and territorial Colleges of Physicians and Surgeons (13), Canadian Medical Association and provincial and territorial counterparts (14), and the Royal College of Physicians and Surgeons. In Group Three there were 16 psychological associations: provincial and territorial Colleges of Psychologists (14), Canadian Psychological Association, and Canadian Association of School Psychologists. Group Four contained a provincially representative sample of 75 school boards with ADHD guidelines available on respective websites. In Group Five there were 25 advocacy groups: Canadian Council for Exceptional Children and provincial and territorial chapters (10), Learning Disabilities Association of Canada and its provincial and territorial counterparts (10), Children and Adults with Attention Deficit Disorders Canada, Canadian Attention Deficit Resource Network, and Attention Deficit Disorder Ontario Foundation. Given their official vested interests in the diagnosis of ADHD - especially Groups One, Two, and Three-it was presumed that each group would have published documents containing diagnostic criteria/guidelines.

\section{Data Gathered}

During the initial phase of document gathering, telephone inquiries to several members of the five principal groups immediately revealed that the majority of the official documents we required were available via their respective websites. Many organizations' sites provided links to other ADHD-related groups' sites, and using a systematic approach that opened/viewed all available links/documents and eliminated duplications, we accessed the sites of all organizations for all five groups. Websites wherein documents were not readily evident were explored using keywords/phrases: ADHD, attention deficit hyperactivity disorder, ADHD diagnostic criteria/guidelines, resource guides for ADHD, ADHD standards of practice, and ADHD programs and services. Email inquiries secured documents not available to group/website nonmembers. For example, the Canadian Medical Association and the Canadian Psychiatric Association only allowed member access to their websites. This comprehensive search resulted in copies of 176 pertinent documents. It is possible that a few somewhat pertinent documents were not obtained (e.g., advocacy or support groups/individuals), but no glaring omissions of imperative documents were noted (e.g., documents for all medical associations were obtained). Each secured document was analyzed according to the analytic framework below.

\section{Analytic Framework}

To compare the secured documents, a three-question analytic framework examined the conceptual components of the ADHD diagnostic process in Canada. The use of the DSM-IV-TR ADHD behavioural criteria in a systematized diagnostic procedure was the overarching standard 
against which documents were compared because "the DSM criteria are based on clinical experience and an expanding research foundation. These criteria have more support in the literature than any other available diagnostic criteria" (American Academy of Pediatrics, 2002, p. 5). This study did not examine ADHD interventions. The three questions and their respective rationales were:

1. What professionals are mandated to assess and diagnose ADHD? A variety of professionals including psychiatrists, psychologists, doctors, and social workers diagnose ADHD in the United States and elsewhere. Based on our analyses (documented in subsequent sections), the manager of Public Inquiries for the Ontario College of Physicians summed up the overall Canadian situation: "a diagnosis of ADHD can be made by any physician in Ontario; however, physicians' licenses stipulate they only practice in areas of medicine in which they are experienced and knowledgeable" (B. Goldig, personal communication, October 21, 2002). Further, it is known that different professionals prescribe different ADHD treatments. For example, for the same diagnosis, psychiatrists could prescribe medication while psychologists could only prescribe behavioural interventions. As McBurnett et al. (1993) reported, "both the accuracy and reliability of DSM diagnoses have been found to be linearly associated with the degree of psychological training and educational attainment" (p. 116). Therefore, it would be important to know which Canadian professionals were responsible for ADHD assessment and diagnosis.

2. Do organizations regulating ADHD recommend assessment procedures? Assessment is broadly defined as an evaluative process that gathers information to make instructional decisions about students. The DSM-IV-TR does not specify a standardized assessment procedure for ADHD (Anastopoulos \& Shelton, 2001) leaving it to the diagnostician's discretion, thus, open to interpretation. Depending on a professional's knowledge and skills, diagnostic inconsistencies are likely. The consensus amongst researchers is that multi-method assessments using the various reliable and valid instruments available is preferred (Quinlan, 2000).

3. Is an underlying ADHD theoretical foundation recommended? This is important because a diagnostician's understanding of the foundational concepts of ADHD and his or her interpretation of the diagnostic criteria determines how, and whether, ADHD is diagnosed. If understandings differ, diagnostic inconsistencies including misdiagnoses, are likely. There is considerable evidence that clinicians favour the dimensional model over the categorical approach (Goldstein, 2000). In the categorical approach, a child must manifest a minimum number of symptoms as well as meet age of onset, impairment, and possible co-occurrence criteria to be diagnosed. If the child is one symptom short, the diagnosis is not affirmed. On the other hand, the dimensional model assumes that everyone exhibits ADHD behaviours from a minimal to a maximal degree; therefore, having all but one symptom would probably result in the diagnosis. Our review of the literature revealed that the consensus amongst researchers is that dimensionally scored symptoms are better predictors for ADHD than categorical measures.

Each of the 176 documents were examined in light of the three analytic questions, resulting in one of three possible answers: (a) Yes, indicated the document had ADHD assessment and diagnostic guidelines and the answer to the relevant question was found within the document; (b) No, indicated the document did not have ADHD assessment and diagnostic guidelines; or (c) Not Identified, indicated organizations did not have pertinent documents or website information, and/or did not respond to e-mail inquiries. 


\section{Results}

The results of the analyses are presented by question in tabular form with accompanying commentary. Only analytically pertinent information related to the three questions is reported below with minimal duplicative reporting. The overly general and minimally pertinent information found in numerous documents is not reported (e.g., the benefits/non-benefits of medication/interventions). Table 1 contains the abbreviations for all organizations in all tables.

Table 1

Summary Abbreviations for Organizations

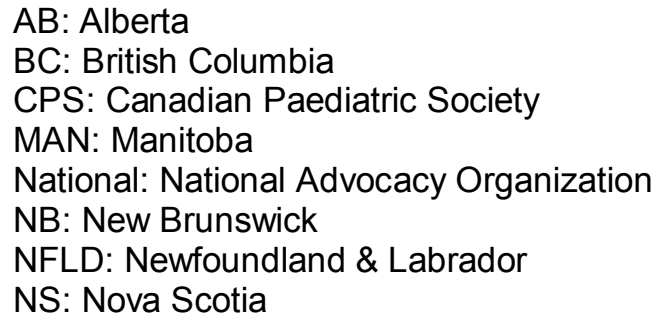

NWT: Northwest Territories

NU: Nunavut Territory

ON: Ontario

PEI: Prince Edward Island

QUE: Quebec

SK: Saskatchewan

YU: Yukon Territory

\section{Question 1: What professionals are mandated to assess and diagnose ADHD?}

The assessment and diagnosis of ADHD is considered a controlled act within the Regulated Health Professions Act, Section 27(2), 1991 (Ontario Ministry of Health, revised 2002):

...communicating to the individual or his/her personal representative, a diagnosis identifying a disease or disorder as the cause of symptoms of the individual in circumstances in which it is reasonably foreseeable that the individual or his/her personal representative will rely on the diagnosis [Section 27(2), p. 1].

Table 2 contains information regarding the professionals eligible to carry out this controlled act.

No ministry of health documents contained information specifically indicating the professionals mandated to assess and diagnose ADHD. Of the 15 ministry of education documents, only Saskatchewan, Manitoba, British Columbia, and Quebec (26\%) indicated that physicians, psychiatrists, and registered psychologists with ADHD training were mandated to assess and diagnose ADHD. All four jurisdictions considered ADHD a medical diagnosis.

The eight medical association documents $(27 \%)$ stated that only member physicians, paediatricians, and psychiatrists were responsible for ADHD diagnosis and emphasized that professionals only practice medicine in areas of expertise. Prince Edward Island indicated that clinical psychologists can also provide ADHD diagnoses.

Three psychological association documents (19\%) indicated that both physicians and qualified psychologists were allowed to assess and diagnose ADHD. In Quebec, these roles were specifically delineated wherein psychologists were responsible for interviews and testing for learning problems and could provide overall impressions, but did not provide diagnoses, while physicians were responsible for medical exams and rendered the ADHD diagnosis. 
Table 2

Professionals Mandated to Diagnose ADHD by Organization

\begin{tabular}{|c|c|c|c|c|}
\hline Organization & $N$ & Physicians only & $\begin{array}{l}\text { Physicians and/or } \\
\text { Psychologists }\end{array}$ & Not identified \\
\hline $\begin{array}{l}\text { Federal/Provincial/Territorial } \\
\text { Ministries of health }\end{array}$ & 15 & $0 \%$ & $0 \%$ & $100 \%(15 / 15)$ \\
\hline $\begin{array}{l}\text { Provincial/Territorial } \\
\text { Ministries of education }\end{array}$ & 15 & $\begin{array}{l}13 \%(2 / 15) \\
\text { (SK \& QUE) }\end{array}$ & $\begin{array}{l}13 \%(2 / 15) \\
(B C \& \text { MAN) }\end{array}$ & $74 \%(11 / 15)$ \\
\hline $\begin{array}{l}\text { Federal/Provincial/Territorial } \\
\text { Medical associations }\end{array}$ & 30 & $\begin{array}{c}27 \%(8 / 30) \\
\text { (NU, SK, BC, QUE, } \\
\text { ON, MAN, CPS) }\end{array}$ & $\begin{array}{c}7 \%(2 / 30) \\
\text { (PEI \& NS) }\end{array}$ & $66 \%(20 / 30)$ \\
\hline Psychological associations & 16 & $\begin{array}{l}\text { 6\% (1/16) } \\
\text { (QUE) }\end{array}$ & $\begin{array}{c}19 \%(3 / 16) \\
(A B, M A N, O N)\end{array}$ & $75 \%(12 / 16)$ \\
\hline School boards & 75 & $\begin{array}{l}4 \%(3 / 75) \\
(A B, Q U E)\end{array}$ & $\begin{array}{c}7 \%(5 / 75) \\
(\mathrm{ON}, \mathrm{AB}, \mathrm{BC})\end{array}$ & $89 \%(67 / 75)$ \\
\hline Advocacy groups & 25 & $\begin{array}{c}16 \%(4 / 25) \\
\text { (National, ON) }\end{array}$ & $\begin{array}{c}4 \%(1 / 25) \\
(\mathrm{ON})\end{array}$ & $78 \%(20 / 25)$ \\
\hline
\end{tabular}

The eight school board documents (11\%) consistently named physicians as eligible to diagnosis ADHD, but eligible psychologists were variably described as registered psychologists, psychological associates, chartered psychologists, or school psychologists. One Alberta board clearly indicated they would only recognize the ADHD diagnosis if provided by a physician.

Four advocacy organization documents $(20 \%)$ indicated that physicians, paediatricians, or psychiatrists were responsible for ADHD diagnoses, while the Learning Disabilities Association of Ontario indicated that psychologists and associates with master's degrees were also allowed. In summary, it appears that physicians and a variety of other professionals can assess and diagnose ADHD in Canada if their professional association considers it part of their standards of practice; however, this specific information was neither easily determined nor was it consistently delineated within or across documents.

Question Two: Do organizations regulating ADHD recommend assessment procedures?

The Royal College of Physicians and Surgeons stated by email that it does not set policy, guidelines, or procedures for physicians; therefore, its document was not included in our analyses. No assessment procedure guidelines were found in any ministry of health documents, probably because ADHD is predominantly the purview of medical associations.

The ministry of education documents of Manitoba, Quebec, British Columbia, and Alberta (40\%) all prescribed ADHD assessment guidelines and outlined various forms of functional 
Table 3

ADHD Assessment Procedure Recommended by Organization

\begin{tabular}{|c|c|c|c|c|}
\hline Organization & $N$ & Yes & No & Not identified \\
\hline $\begin{array}{l}\text { Federal/Provincial/Territorial } \\
\text { Ministries of health }\end{array}$ & 15 & $0 \%$ & $0 \%$ & $100 \%(15 / 15)$ \\
\hline $\begin{array}{l}\text { Provincial/Territorial } \\
\text { Ministries of education }\end{array}$ & 15 & $\begin{array}{c}27 \%(4 / 15) \\
\text { (MAN, QUE, BC, AB.) }\end{array}$ & $\begin{array}{c}13 \%(2 / 15) \\
(\mathrm{SK}, \mathrm{ON})\end{array}$ & $60 \%(9 / 15)$ \\
\hline $\begin{array}{l}\text { Federal/Provincial/Territorial } \\
\text { Medical associations }\end{array}$ & 30 & $\begin{array}{c}13 \%(4 / 30) \\
\text { (BC, MAN, QUE, CPS) }\end{array}$ & $\begin{array}{c}17 \%(5 / 30) \\
\text { (ON, NS, NB, SK, } \\
\text { NU) }\end{array}$ & $70 \%(21 / 30)$ \\
\hline Psychological associations & 16 & $\begin{array}{l}\text { 6\% (1/16) } \\
\text { (QUE) }\end{array}$ & $\begin{array}{c}19 \%(3 / 16) \\
\text { (MAN, ON, AB) }\end{array}$ & $75 \%(12 / 16)$ \\
\hline School boards & 75 & $\begin{array}{l}3 \%(2 / 75) \\
\text { (QUE) }\end{array}$ & $\begin{array}{l}8 \%(6 / 75) \\
(\mathrm{AB}, \mathrm{ON})\end{array}$ & $89 \%(67 / 75)$ \\
\hline Advocacy groups & 25 & $\begin{array}{c}8 \%(2 / 25) \\
\text { (National, ON) }\end{array}$ & $\begin{array}{l}8 \%(2 / 25) \\
\text { (ON, QUE) }\end{array}$ & $84 \%(21 / 25)$ \\
\hline
\end{tabular}

behavioural assessment, defined as a systematic process, carried out by individuals or multidisciplinary teams, that analyzes problem behaviour, conditions of the behaviour, and the function the behaviour serves, and uses direct observation and frequency checklists to confirm that function.

Four national, provincial, and territorial medical association documents (13\%) provided minimal ADHD assessment guidelines. One document was a one-page summary reviewing prescription medication for $\mathrm{ADHD}$, one was too general to be relevant for diagnosticians, and a third contained adult ADHD assessment guidelines, but not for children/adolescents. While the Canadian Paediatric Society implemented DSM-IV criteria according to guidelines from three American sources, we determined that the criteria were so varied they would make the diagnostic task more difficult, rather than easier. Nonetheless, it was noteworthy that one of the sources, the US National Institutes of Health (2007), strongly advocated for more consistent assessment procedures, clearly suggesting dissatisfaction with how physicians utilize ADHD procedures.

The ADHD guidelines co-published by le College des medecins du Quebec and l'Ordre des psychologies du Quebec (2001) were the only comprehensive procedures found in the entire data set. We provide an overview of the translated guidelines found in Le Trouble Deficit de l'Attention/Hyperactivite et l'Usage de Stimulants du Systeme Nerveux Central:

1. The diagnosis requires a multi-disciplinary process carried out by both physicians (physical exam, cognitive testing, imaging, or lab tests for co-occurring disabilities) and psychologists (all required interviews investigating the child's symptoms and behaviours, social integration, family relationships, school and home environments, report cards, attempted behavioural interventions, his/her teacher's knowledge of $\mathrm{ADHD}$, and required psychometric testing to support the above findings). 
2. There are three phases in the diagnostic process: (a) interviews of parents, teachers, and/or child including the child's complete history; (b) hypothesis formulation; and (c) confirmation of the hypothesis via analyses of DSM-IV-TR criteria.

3. Assessors are to use DSM-IV-based questionnaires (i.e., Achenbach Scale, Asselin-Poulin Scale, Conner's Scale, Parental Stress Inventory) to clarify their hypothesis and discount comorbidity.

Of the 75 school board documents, only 2 from Quebec referred to guidelines from Working Together to Provide Better Support for Young People: ADHD - AttentionDeficit/Hyperactivity Disorder: Plan of Action (Gouvernement du Quebec Ministere de l'Education \& Ministere de la Sante et des Services Sociaux, 2000), but the documents did not provide specific assessment procedures. Further enquiries determined that all Quebec school boards were to use these guidelines.

The Attention Deficit Resource Network document contained general guidelines regarding what to expect in ADHD assessments, while the Learning Disabilities Association of Ontario document merely mentioned ADHD as a co-existing disorder with LD. In summary, other than in Quebec, there was a glaring absence of specific assessment procedures for ADHD across Canada and it is clear that the Canadian medical establishment does not have specific guidelines despite the pervasive view that ADHD is a medical condition. This is particularly problematic given that paediatricians probably provide most ADHD diagnoses due to the age-of-onset criteria of 7 years.

\section{Question 3: Is an underlying ADHD theoretical foundation recommended?}

An underlying theoretical foundation was deemed evident if a document recommended that ADHD diagnoses, guidelines, or procedures be derived from dimensionally scored criteriathe consensus position in the literature (Goldstein, 2000; Zentall, 2006). The data revealed that there were no ADHD theoretical foundations found in any provincial or territorial ministry of health documents. Of the medical association documents, one (MAN) suggested that other ADHD theoretical foundations could be considered, but provided no details. In the most clearly worded guidelines examined in this study, the Quebec document encouraged the consideration of a differential diagnosis resulting from a multidisciplinary assessment scored dimensionally and it encouraged physicians to keep abreast of evolving information regarding ADHD. A differential diagnosis includes an examination for co-existing conditions such as learning disabilities, conduct disorder, oppositional defiant disorder, and mood or anxiety disorders. The BC document stated that health professionals making an ADHD diagnosis should use DSM-IV-TR criteria to reduce the over prescription of medication. While the medical associations of Alberta, British Columbia, Manitoba, and Quebec, and the Canadian Paediatric Society had established guidelines, the other provincial associations did not; Prince Edward Island follows the Canadian Paediatric Society's guidelines.

There were no consensus guidelines amongst the psychological association documents, but all associations expected members to use the most empirically supported criteria available (not specified). This suggests that each psychologist could use different diagnostic criteria. Of the 75 school board documents, none had their own guidelines and only the 2 from Quebec directly referred to guidelines in documents from their medical association. All $\mathrm{BC}$ school boards were to follow Ministry of Education guidelines to receive ADHD-related funding. All of the advocacy group documents were obviously designed to increase understanding of ADHD. 
Table 4

ADHD Theoretical Foundation by Organization

\begin{tabular}{|c|c|c|c|c|}
\hline Organization & $N$ & $\begin{array}{c}\text { Yes } \\
\text { DSM-IV }\end{array}$ & $\begin{array}{c}\text { Yes } \\
\text { Functional Beha- } \\
\text { vioural Assessment }\end{array}$ & $\begin{array}{c}\text { No or } \\
\text { not identified (NI) }\end{array}$ \\
\hline $\begin{array}{l}\text { Federal/Provincial/Territorial } \\
\text { Ministries of health }\end{array}$ & 15 & $0 \%$ & $0 \%$ & $100 \%(15 / 15)$ \\
\hline $\begin{array}{l}\text { Provincial/Territorial } \\
\text { Ministries of education }\end{array}$ & 15 & $\begin{array}{c}13 \%(2 / 15) \\
(B C, A B)\end{array}$ & $\begin{array}{l}7 \%(1 / 15) \\
\text { (MAN) }\end{array}$ & $\begin{array}{c}20 \%(3 / 15) \text { (QUE, } \\
\text { SK, ON) } \\
\text { NI: } 60 \%(9 / 15)\end{array}$ \\
\hline $\begin{array}{l}\text { Federal/Provincial/Territorial } \\
\text { Medical associations }\end{array}$ & 30 & $\begin{array}{c}27 \%(8 / 30) \\
(B C, A B, M A N, \\
\text { QUE, CPS, ON, } \\
\text { PEI, SK) }\end{array}$ & $0 \%$ & $\begin{array}{c}7 \%(2 / 30)(\mathrm{NS}, \mathrm{NB}) \\
\mathrm{NI}: 66 \%(20 / 30)\end{array}$ \\
\hline Psychological associations & 16 & $\begin{array}{l}13 \%(2 / 16) \\
\text { (QUE, ON) }\end{array}$ & $\begin{array}{c}19 \%(3 / 16) \\
(M A N, O N, A B)\end{array}$ & $\begin{array}{c}13 \%(2 / 16)(\mathrm{MAN}, \\
\mathrm{AB}) \\
\mathrm{NI}: 75 \%(12 / 16)\end{array}$ \\
\hline School boards & 75 & $\begin{array}{l}5 \%(4 / 75) \\
\text { (QUE, BC) }\end{array}$ & $0 \%$ & $\begin{array}{c}8 \%(6 / 75)(\mathrm{AB}, \mathrm{ON}) \\
\mathrm{NI}: 87 \%(65 / 75)\end{array}$ \\
\hline Advocacy groups & 25 & $\begin{array}{l}4 \%(1 / 25) \\
\text { (National) }\end{array}$ & $0 \%$ & $\begin{array}{c}12 \%(3 / 25) \\
\text { NI: } 84 \%(21 / 25)\end{array}$ \\
\hline
\end{tabular}

The Attention Deficit Disorder Foundation of Ontario recommended that professionals follow the DSM-IV-TR-based guidelines of the American Academy of Pediatrics.

In summary, the data revealed that other than in Quebec, the overall procedures in Canada for diagnosing ADHD were not strongly and/or explicitly supported by empirical or theoretical underpinnings other than a few casual references to the DSM-IV-TR. This was also the case for our examinations for dimensionally scored criteria.

\section{Summary and Conclusions}

Students with ADHD typically exhibit varied but unique sets of behaviours that need specialized assessment and precisely designed interventions. Because educators are often frustrated by their inability to consistently help these students, we surmised that inconsistencies in the assessment and diagnosis process were contributing to these frustrations in that a lack of diagnosis cohesion is apt to lead to inappropriate decision-making regarding treatment. Therefore, this study sought to determine whether the interpretation and application of ADHD assessment and diagnostic criteria and procedural guidelines demonstrated a consistent and thus, reliable, approach in Canada. An analytic framework enabled critical analyses and highlighted the similarities and differences amongst the criteria and guidelines. More importantly, the comprehensiveness of the framework was confirmed by the non-emergence of other questions crucial to determining the consistency issue. 


\section{Professional Responsibility?}

Outside of physicians and qualified psychologists, it was unclear which Canadian professionals were charged with assessing and diagnosing ADHD. While there was general agreement that qualified health professionals were responsible, one had to infer that this meant those with specialized training, but there were no definitively excluded professionals such as physicians or therapists without any ADHD training. It was evident that ADHD assessment and diagnosis was not the sole purview of one professional association and that several other professionals were mandated to diagnose ADHD if a regulating body stated that their members were eligible. Furthermore, while diagnosing ADHD was variously considered a controlled act, restricted activity, or reserved action, each term was evidently interpretable. If the intent of provincial health professions' legislation is to protect the public by regulating the practice of its professionals, then the assessment and diagnosis of ADHD has not received due attention.

It is not difficult to hypothesize about the compounding problems that would arise from inconsistent diagnoses due to inconsistent diagnostic perspectives due to inconsistent criteria and nearly non-existent procedural guidelines. First, the diagnosis will lack credibility. Given that some are already skeptical about ADHD, its identifying criteria, and/or its diagnosis, this level and type of consistent inconsistency is problematic. Second, behavioural or medical interventions based on such diagnoses become suspect for efficacy. While this is also problematic and needs to be resolved, it might very well explain the apparent lack of educator success when providing or facilitating ADHD interventions. Students with ADHD and their teachers and parents are poorly served when they have to rely on an inconsistent diagnosis to solve a behavioural issue that can have considerable educational and social consequences.

\section{Assessment Procedure?}

Except for psychological and medical associations, the vast majority of other organizations had no ADHD assessment criteria or guidelines; therefore, it was very difficult to assess their procedures for consistency. For the few others that outlined criteria and guidelines, these descriptions often only addressed the over-prescription of stimulant medication and none addressed behavioural interventions. If medical and psychological associations were sincerely concerned about the over-prescription of medication, one would assume that they would go to greater lengths to ensure more comprehensive and consistent guidelines. This lack of definitive assessment guidelines confirms Anastopoulos and Shelton's (2001) assertion that the diagnosis of ADHD is open to interpretation by the very professionals charged with its responsibility; thus, inconsistencies are not only possible, they are probable.

On the other hand, the Quebec initiative provided comprehensive guidelines that would be an excellent model for all vested organizations. It contains explicit guidelines governing ADHD diagnoses by health professionals and educators that could be implemented by multidisciplinary teams to provide valid and reliable diagnoses, which would translate into enhanced reliability and consistency. Moreover, this approach ensures that all Quebec professionals have knowledge of each other's roles and responsibilities and of the desired assessment standards. Not only does this provide consistency, it fosters a climate of consistency within which anomalies and inconsistencies are noticed and properly addressed, instead of being considered a diagnostician's prerogative. 


\section{Theoretical Foundation?}

Despite not having specific ADHD diagnostic criteria and guidelines, the majority of organizations inferred that diagnosing professionals use the DSM-IV-TR as their theoretical foundation. Another advantage of Quebec's guidelines was an explicit description of the diagnostic application of each DSM-IV-TR criteria. This explicitness not only forms an overarching direction for the process, it provides more consistency in diagnoses and would raise red flags for inconsistencies and anomalies.

Unfortunately, a few organizations indicated that members could also use other diagnostic criteria and guidelines, such as the International Classification of Diseases-10 from the World Health Organization (WHO, 1993). Although similar, the ICD-10 is used to diagnose the more narrowly defined "hyperkinetic disorder," not to identify children who experience the distinct inattentive, hyperactive, or impulsive subtypes of ADHD as defined by DSM-IV-TR. Given the cascade of potential inconsistencies previously mentioned, the fact that diagnosticians could have an optional theory of ADHD is troubling. On the other hand, other jurisdictions suggested the use of complementary theoretical foundations, such as functional behavioural assessments, to complement the ADHD diagnosis. The literature supports functional behavioural assessments as having legitimate conceptual roots (Landrum \& Kauffman, 2006) and as producing more effective psychosocial interventions because they are behaviourally based rather than medically derived (Zentall, 2006).

It was evident that advocacy groups and school boards left the diagnostic process to physicians; many only officially recognized the ADHD diagnoses when determined by doctors. While this may be technically correct, the more collaborative processes described in the Quebec and Manitoba documents appear to be better approaches. Even though physicians still make the final diagnosis, educators and advocacy groups can play key roles by keeping abreast of ADHD developments and by bringing them to bear on the collaborative process they are involved in, not excluded from.

\section{Implications for Education Stakeholders}

Similar to Cohen's (2006) findings, this study revealed that ADHD assessment and diagnosis in Canada is a poorly controlled process that lacks explicit theoretical foundations and/or implementation principles. These findings have several implications for education stakeholders in Canada. First, educators should demand from the medical community a more rigorous standardization for ADHD diagnoses. Comparing the ADHD state of affairs with that of learning disabilities (LD), it is clear that LD has explicit and standardized guidelines while ADHD does not. Following standardized assessment criteria and guidelines for LD based on well established theoretical constructs (see Lerner \& Kline, 2006), teachers observe student learning and successfully modify assignments and develop effective Individualized Education Programs. This successful approach is directly related due to the explicit involvement of psychologists and special educators who collectively assess, diagnose, and design and provide educational interventions. Their inherent proximity to the child and his/her problems provides a vested interest to continually refine the process. Conversely, physicians who diagnose ADHD are not privy to the day-to-day behavioural challenges faced by students, parents, and educators. Medical professionals only see referred children for very short periods, have little, if anything, to do with non-medication interventions, and are not exposed to the constant strife caused by ADHD (Na- 
tional Association of School Psychologists, 2002). Can it be that the medical establishment does not consider ADHD a serious enough problem to warrant a consistent approach? It may be that educators have to bring their urgency for consistent ADHD diagnosis to the medical profession.

Second, education stakeholders need to demand a primary role in the ADHD diagnostic and intervention process. This, in addition to specialized training in ADHD, would enhance interactive consultation between educators and health professionals. Despite their invaluable firsthand knowledge of in-class behaviours, continuing to consider ADHD as a purely medical diagnosis may be absolving educators of their responsibility in its diagnostic process, thereby partly absolving them of intervention responsibilities (Baum \& Olenchak, 2002).

The findings of this study have highlighted some of the conceptual similarities inherent in the diagnostic guidelines across Canada. We provide three recommendations to move the field towards a uniform, and thus, more consistent approach to ADHD diagnosis.

Recommendation 1: Agree on the DSM-IV-TR criteria as the preferred assessment criteria and standardize all diagnostic guidelines to suit. The theoretical foundations underpinning the DSM-IV-TR definition and behavioural criteria provide the gold standard for ADHD assessment. Strictly adhering to these foundational elements would ensure that diagnosticians would only use instruments founded upon the DSM-IV-TR definition. The Quebec diagnostic guidelines and specific data gathering processes cited earlier would be an excellent framework to emulate. This would provide more consistency across assessment procedures, interpretations of assessment results, and the design of suitable interventions.

Recommendation 2: Adopt a multidisciplinary approach for the assessment of $A D H D$. This would prevent physician-only diagnoses and the pharmacological-only interventions that have predominated to this point. Professionals in health and education are privy to different but overlapping first-hand understandings of a child's situation and both need to contribute their respective insights. Multidisciplinary information should include medical examinations (physicians), behavioural observations (psychologists), school and classroom functioning (educators), social and community functioning (parents), and functional behavioural assessments conducted by educators. Given that educators are mostly responsible for students with ADHD, educators with specialized training in ADHD should lead the multidisciplinary process as they do the IEP process.

Recommendation 3: All educators should receive specialized training in ADHD. Relative to their role in students' lives, each educator should participate in professional development specifically designed to inform them of ADHD theory, assessment criteria and guidelines, and interventions. ADHD education should also be required in teacher preparation programs and for teacher certification. This would heighten overall awareness, invoke earlier referrals by teachers, and inform all educators of their potential roles in the multidisciplinary assessment process.

\section{Future Possibilities}

For obvious reasons, the assessment and diagnosis of ADHD in Canada is a challenge for all education stakeholders. For equally obvious reasons, it does not have to be. The theoretical underpinnings and definitional criteria for ADHD are reliably and validly established, but its as- 
sessment and diagnosis in Canada is questionable due to glaring inconsistencies in application. Excellent ADHD diagnostic assessment instruments exist (Zentall, 2006) and exemplary interventions for ADHD have been devised (Lane et al., 2006). All other categories of exceptionality enjoy the benefits of working within established, standardized, and consistent assessment and diagnosis guidelines to produce appropriate interventions. The problem is that the medical profession has no immediate or tangible motivation to consolidate their professional diagnostic responsibilities around common guidelines. No doubt their motivation is inversely proportional to their proximity to students with ADHD. The multidisciplinary approach holds great promise. Given educators' abilities to adapt to ever-changing educational conditions, it is not difficult to extrapolate the school-based team model to the governance of assessing students with ADHD.

\section{Websites Examined}

Attention Deficit Disorder Ontario (ADDO): http://www.addofoundation.org/info.htm British Columbia Education (n.d.): http://www.bced.gov.bc.ca/specialed/adhd/

Canadian Association of School Psychologists: http://www.stemnet.nf.ca/casp/

Canadian Council for Exceptional Children: http://www.cec.sped.org

Canadian Paediatric Society: http://www.cps.ca/english/

Canadian Psychiatric Association: http://www.cpa-apc.org/

Canadian Psychological Association and provincial/territorial counterparts: http://www.cpa.ca/ inprovinces.html

CHADD Canada: http://www.chaddcanada.org

College of Physicians \& Surgeons of British Columbia (n.d.): https://www.cpsbc.ca/node/130

College of Physicians \& Surgeons of Manitoba (2002): http://www.umanitoba.ca/colleges/

physicians_and_surgeons/Guidelines_and_Statements/1300.html

Health Canada: http://www.hc-sc.gc.ca/english/care/index.html

Learning Disabilities of Canada/provincial/territorial counterparts: http://www.ldac-taac.ca/english/

ldac.htm

Manitoba Education (n.d.): http://www.edu.gov.mb.ca/ks4/specedu/beh/pdf/7.pdf

Ontario Medical Association (2002): http://www.oma.org

Ontario Ministry of Education (1980): http://www.mettowas21.edu.gov.on.ca/eng/general/elemsec/

speced/edact/html

Provincial/Territorial Colleges of Physicians \& Surgeons: http://www.umanitoba.ca/colleges/cps

Provincial/Territorial Health Ministry links: http://www.hc-sc.gc.ca/english/care/provincial.html

http://www.casa.ca/education_links_e.shtml\#link3

Provincial/Territorial Medical Associations: http:/www.cair.ca/links/

index.asp?nts $=\% 80 \% \mathrm{~A} 6 \% \mathrm{~B} 1 \% \mathrm{~A} 3 \% 97 \% \mathrm{C} 0 \% \mathrm{~B} 4 \% \mathrm{AB} \% 89 \% 84 \% 83 \#$ coollinks_cat_14

School Boards: http://www.oise.utoronto.ca/ mpress/eduweb/edboards.html 


\section{References}

American Academy of Pediatrics (2002). Diagnosis and evaluation of the child with attentiondeficit/hyperactivity disorder. [Electronic version]. Pediatrics, 105(5), 1158-1170.

American Psychiatric Association (1952). Diagnostic and statistical manual of mental disorders (1st ed.). Washington, DC: Author.

American Psychiatric Association (1968). Diagnostic and statistical manual of mental disorders (2nd ed.). Washington, DC: Author.

American Psychiatric Association (1980). Diagnostic and statistical manual of mentaldisorders (3rd ed.). Washington, DC: Author.

American Psychiatric Association (1987). Diagnostic and statistical manual of mental disorders (3rd ed., revised). Washington, DC: Author.

American Psychiatric Association (1994). Diagnostic and statistical manual of mental disorders (4th ed.). Washington, DC: Author.

American Psychiatric Association (2000). Diagnostic and statistical manual of mental disorders (4th ed., text rev.). Washington, DC: Author.

Anastopoulos, A., \& Shelton, T. L. (2001). Assessing attention-deficit/hyperactivity disorder. New York: Kluwer Academic/Plenum Publishers.

Barkley, R. (1990). Attention-deficit hyperactivity disorder: A handbook for diagnosis and treatment. New York: The Guildford Press.

Baum, S., \& Olenchak, F. (2002). The alphabet children: GT, ADHD and more. Exceptionality, 10(2), 7791.

Breton, J. J., Bergeron, L., Valla, J. P., Berthiaume, C., Gaudet, N., Lambert, J., et al. (1999). Quebec child mental health survey: Prevalence of DSM-III-R mental health disorders. Journal of Child Psychology \& Psychiatry, 40, 375-384.

Canadian Paediatric Society (2002). The use of stimulant medication in the treatment of attention deficit hyperactivity disorder. Paediatrics \& Child Health, 7(10), 693-696.

Castellanos, F. X., \& Tannock R. (2002). Neuroscience of attention-deficit/hyperactivity disorder: The search for endophenotypes. Nature Reviews Neuroscience, 3, 617-628.

Centre for ADHD/ADD Advocacy Canada (2007). What is ADHD? Retrieved November 24, 2007, from http://www.caddac.ca/cms/page.php?67.

Cohen, D. (2006). How does the decision to medicate children arise in cases of 'ADHD'? Views of parents and professionals in Canada. In G. Lloyd, J. Stead, \& D. Cohen (Eds.), Critical new perspectives on $A D H D$ (pp. 137-155). London: Routledge.

College des medecins du Quebec \& de l'Ordre des psychologies du Quebec (2001). Le trouble deficit de l'attention/hyperactivite et l'usage de stimulants du systeme nerveux central. Montreal, QC: Author.

DuPaul, G. J., Eckert, T. L., \& McGoey, K. E. (1997). Interventions for students with attentiondeficit/hyperactivity disorder: One size does not fit all. School Psychology Review, 26(3), 369381.

Edmunds, A. L., \& Edmunds, G. A. (2008). Special education in Canada. Toronto, ON: McGraw-Hill Ryerson.

Faraone, S.V., Sergeant, J., Gillberg, C., \& Biederman, J. (2003). The worldwide prevalence of ADHD: Is it an American condition? World Psychiatry, 2(2), 104-113.

Goldstein, S. (2000). Categorical or dimensional models: Which is best for ADHD? Retrieved November 2004, from http://www.samgoldstein.com/articles/0207.html

Goldstein, S. A. (1995). Understanding and managing children's classroom behavior. New York: WileyInterscience Publication.

Gouvernement du Quebec Ministere de l'Education \& Ministere de la Sante et des Services Sociaux (2000). Working together to provide better support for young people. ADHD Attentiondeficit/hyperactivity disorder: Plan of action. Quebec, Canada: Author. 
Gresham, F. M. (2002). Social skills assessment and instruction for students with emotional and behavioral disorders. In K. L. Lane, F. M. Gresham, \& T. E. O'Shaunessey (Eds.), Interventions for children with or at risk for emotional and behavioral disorders (pp. 242-258). Boston: Allyn \& Bacon.

Landrum, T. J., \& Kauffman, J. M. (2006). Behavioral approaches to classroom management. In C. M. Evertson \& C. S. Weinstein (Eds.), Handbook of classroom management: Research, practice and contemporary issues (pp. 47-71). Mahwah, NJ: Lawrence Erlbaum Associates.

Lane, K., Falk, K., \& Wehby, J. (2006). Classroom management in special education classrooms and resource rooms. In C. M. Evertson \& C. S. Weinstein (Eds.), Handbook of classroom management: Research, practice and contemporary issues (pp. 439-460). Mahwah, NJ: Lawrence Erlbaum Associates.

Lerner, J. W., \& Kline, F. (2006). Learning disabilities and related disorders: Characteristics and teaching strategies. Boston: Houghton Mifflin Company.

Maag, J. W. (2004). Behavior management: From theoretical implications to practical applications (2nd ed.). Belmont, CA: Thompson Wadsworth.

Martinussen, R., Hayden, J., Hogg-Johnson, S., \& Tannock, R. (2005). Metaanalysis of working memory impairments in children with attention-deficit/hyperactivity disorder. Journal of the American Academy of Child and Adolescent Psychiatry, 44(4), 377-384.

Mather, N., \& Goldstein, S. (2001). Learning disabilities and challenging behaviors. Baltimore: Paul H. Brookes Publishing Co.

McBurnett, K., Lahey, B., \& Pfiffner, L. (1993). Diagnosis of attention deficit disorders in DSM-IV: Scientific basis and implications for education. Exceptional Children, 60(2), 108-117.

McInnes, A., Humphries, T., Hogg-Johnson, S., \& Tannock, R. (2003). Listening comprehension and working memory are impaired in attention-deficit/hyperactivity disorder irrespective of language impairment. Journal of Abnormal Child Psychology, 31(4), 427-443.

Mercugliano, M., Power, T., \& Blum, N. (1999). The clinician's practical guide to attentiondeficit/hyperactivity disorder. Baltimore: Paul H. Brookes.

National Association of School Psychologists (2002). Pediatricians' preferences for ADHD information from schools. School Psychology Review, 31(1), 94.

National Institutes of Health (2007). Interdisciplinary research networks on ADHD. U. S. Department of Health and Human Services. Author. Retrieved November 2004, from http://grants.nih.gov/ grants/guide/rfa-files/RFA-MH-01-012.html

Ontario Ministry of Health (2002). Regulated health professions act, Section 27(2)1, 1991. Retrieved from http://www.elaws.gov.on.ca/DBLaws/Statutes/English/91r18_e.htm\#P228_13636

Quinlan, D. (2000). Assessment of attention-deficit/hyperactivity disorder and comorbidities. In T. Brown (Ed.), Attention-deficit disorders and comorbidities in children, adolescents, and adults (pp. 455507). Washington, DC: American Psychiatric Press.

Rief, S. F. (2005). How to reach and teach children with ADD/ADHD: Practical techniques, strategies, and interventions (2nd ed.). San Francisco: Jossey-Bass.

Roberts, W., Humphries, T., \& Andras, M. (1989). A clinical approach to attention problems. The Canadian Journal of Pediatrics, 9-21.

Sanford, M., \& Ridley, T. (1995). Addressing attention deficit hyperactivity disorder. Canadian Journal of Continuing Medical Education, 7, 117-126.

Seidman, L. J. (2006). Neuropsychological functioning in people with ADHD across the lifespan. Clinical Psychology Review, 26(4), 466-485.

Shea, S., \& Baren, M. (1996). What ADHD is and isn't...and what to do. Patient Care Canada, 7(7), 2651.

Silver, L. (1999). Attention-deficit/hyperactivity disorder (2nd ed.). Washington, DC: American Psychiatric Press.

Szatmari P., Offord D. R., \& Boyle, M. H. (1989). Ontario child health study: Prevalence of attention deficit disorder with hyperactivity. Journal of Child Psychology \& Psychiatry, 30, 219-230. 
Willcutt, E. G., Pennington, B. F., Olson, R. K., Chhabildas, N., \& Hulslander, J. (2005). Neuropsychological analyses of co-morbidity between reading disability and attention-deficit/hyperactivity disorder: In search of the common deficit. Developmental Neuropsychology, 27, 35-78.

Wolraich, M. (2002). Attention-deficit/hyperactivity disorder: Issues for the pediatric office. Pediatric Annals, 31(8), 469.

World Federation for Mental Health. (2004). Without boundaries - Challenges and hopes for living with ADHD: An international survey. Retrieved November 26, 2007, from http://www.wfmh.org

World Health Organisation (1993). The ICD-10 classification of mental and behavioural disorders: Clinical descriptions and diagnostics guidelines (pp. 155-157). Geneva: WHO.

Zentall, S. S. (2006). ADHD and education: Foundations, characteristics, methods, and collaboration. Columbus, $\mathrm{OH}$ : Pearson Education.

Zentall, S. S., \& Stormont-Spurgin, M. (1995). Educator preferences of accommodations for students with attention-deficit hyperactivity disorder. Teacher Education and Special Education, 18(2), 115-123.

\section{Author's Note}

Correspondence concerning this article should be addressed to Alan Edmunds, 1106 Faculty of Education, 1107 Western Road, London, ON N6G1G7. E-mail: aedmunds@uwo.ca 